$$
\begin{aligned}
& \text { عبد الرحمن عبد الفتاح محمد بشار محمد النجداوي }
\end{aligned}
$$

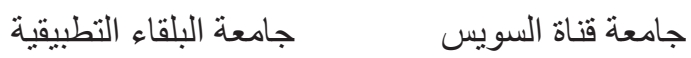

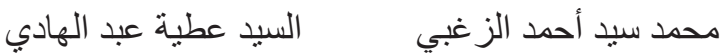

جامعة قناة السويس

يهدف البحث إلى در اسة بعض العوامل المؤثرة على دور ان العمالة في مطاعم الوجبات السريعة في مدينة عمان، و التي تتمثل في مجال رضا فيا

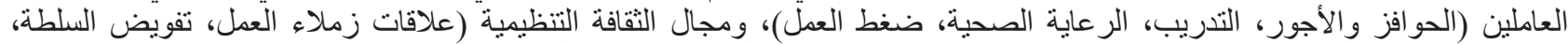

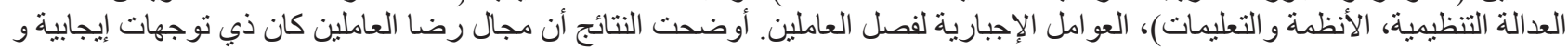

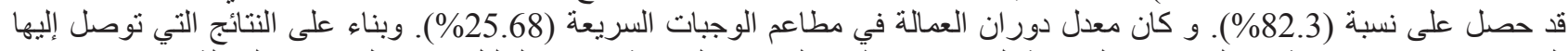

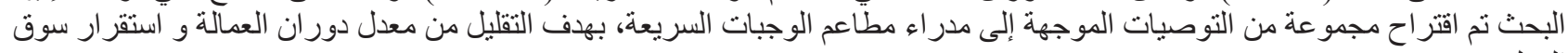

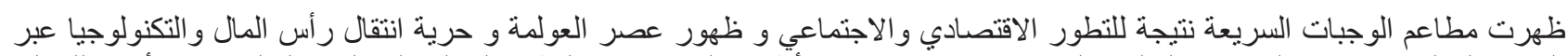

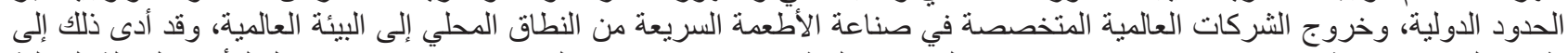

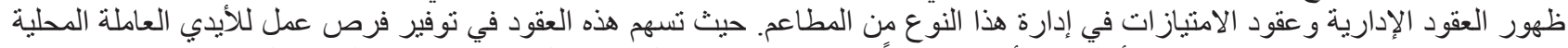

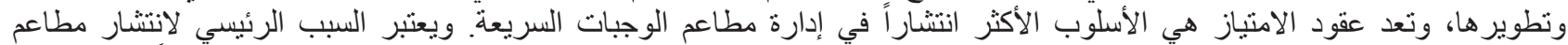

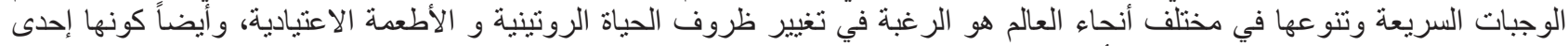

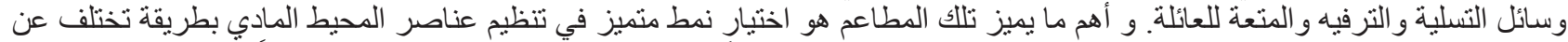

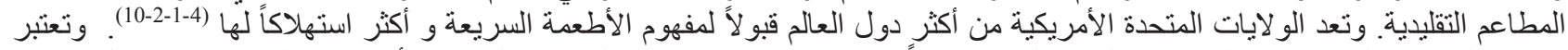

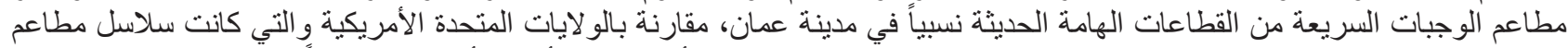

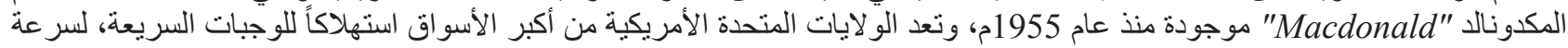
تقبلهم مفهوم مطاعم الوجبات السريعة.

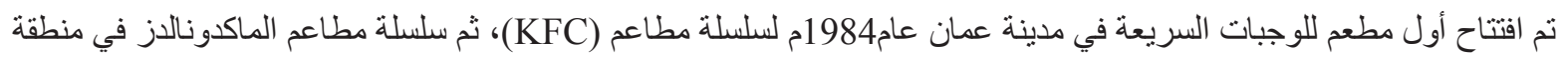

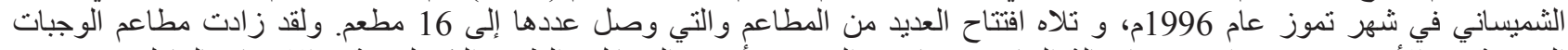

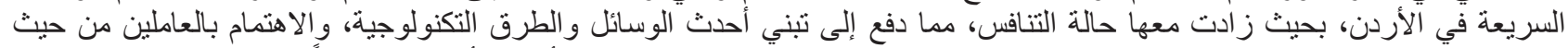

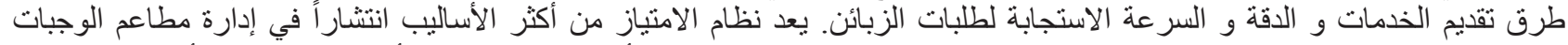

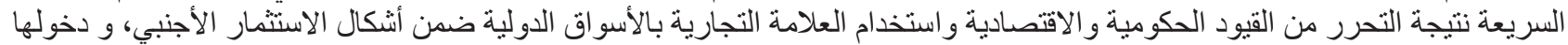

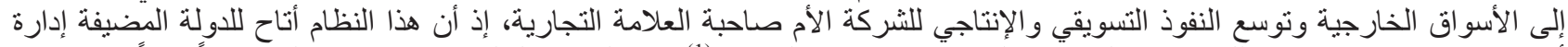

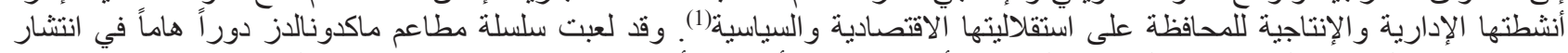

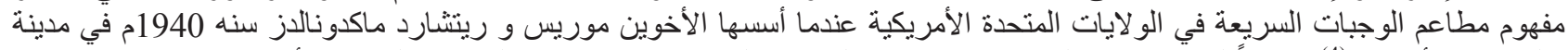

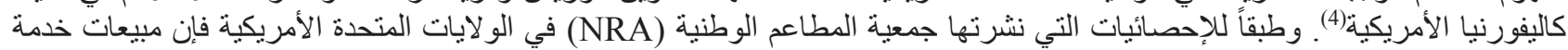

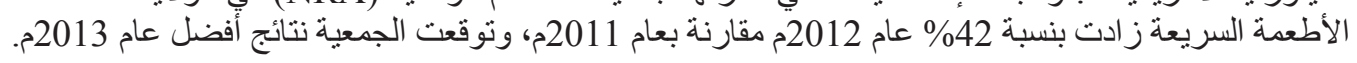

تعرف الوجبات السريعة على أنها " الوجبات التي يمكن أن يتم تجهيز ها وتحضيرها في فترة وجيزة من الزمن، و تمتاز مطاعم

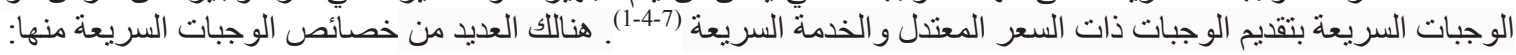

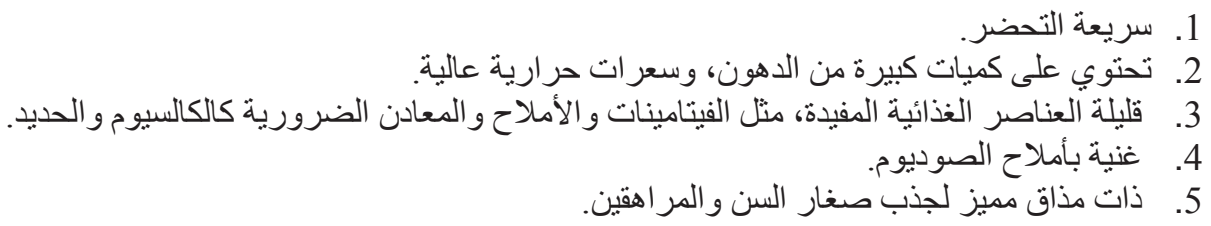

أهمية البحث

تكمن أهمية البحث في در اسة بعض العو امل المؤثرة على دوران العمالة في مطاعم الوجبات السريعة في مدينة عمان المتمثلة في مجال رضا

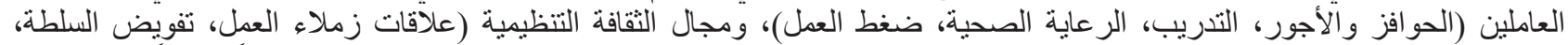

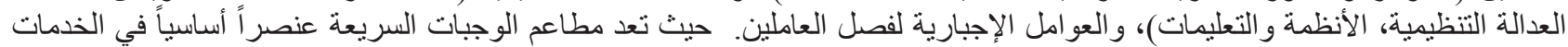


السياحية المحلية أو الأجنبية في الأردن ولا تقل أهمية عن الخدمات التي تقدمها الفنادق، إذ أنها تعتبر ميزة تنافسية لكثير من البلدان، ويعود

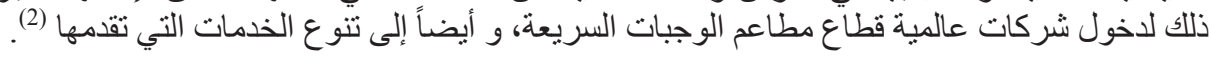

أهداف البحث

- - يهذف البحث إلى دراسة بعض أسباب دوران العمالة في مطاعم الوجبات السريعة في مدينة عمان المتمثلة في رضا العاملين، الثقافة التنظيمية، العوامل الإجبارية لفصل العاملين.

- تحديد مستوى دوران العمالة في مطاعم الوجبات السريعة في مدينة عمان باستخدام معادلات رياضية لمعرفة مدى استقرار العمالة في هذا القطاع الهام.

- - التوصل إلى بعض التوصيات لإدار ات مطاعم الوجبات السريعة في مدينة عمان، لمعالجة ظاهرة زيادة معدلات دوران العمالة و التقليل من

منهجية البحث مثن

مجتمع البحث والعينة

استخدام الباحث المنهج التحليلي الوصفي في تحليل نتائج البحث باستخدام برنامج (SPSS)

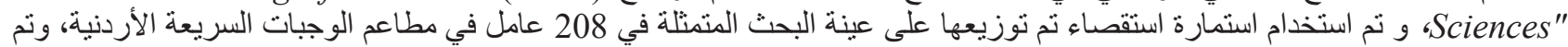

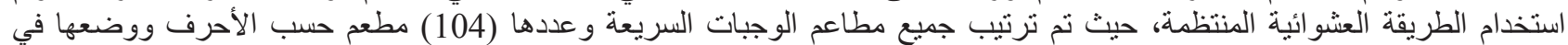
تسلسل رقمي من(1-104) ,و ونم اختيار 31 مطعم مثلت 30\% من مجتمع المطاعم، كما تم جمع بيانات دور عدة

العمالة من مدر اء المو ارد البشرية في شركات مطاعم الوجبات السريعة في مدينة عمان البالغ عددهم (21) مديرًا.

تم حساب معدل دور ان العمالة من خلال المعادلة التالية بما يتفق مع البيانات التي تم جمعها من مطاعم عينة الدر اسة:

متوسط عدد العاملين خلال فترة محدة = عدد الأفراد في بداية الفترة + عدد الأفراد في نهاية الفترة

معدل دوران العمالة = عدد العاملين التاركين للعمل خلال فترة

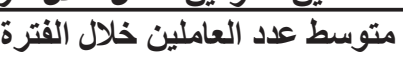

أساليب التحليل الإحصائي

1) المتوسط الحسابي: و الذي يمثل أهم مقياس من مقاييس النزعة المركزية للبيانات لأنه يعبر عن رأي أفر اد العينة ومدى أهمية كل

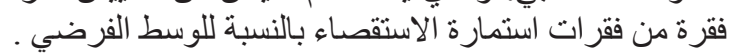

2) الانحر اف المعياري: يعتبر أهم مقياس من مقاييس التشتت للبيانات، لتعبيره عن مدى اتفاق استجابات عينة الدراسة عن كل فقرة أو بـ مجال.

3) التوزيعات التكر ارية: لإظهار خصائص عينة الدر اسة، ونسبة المو افقة والتي ترتبط بالمتوسط الحسابي .

4) معاملات ارتباط بيرسون (Person Correlation) لمعرفة العلاقة الارتباطية بين مستويات رضا العاملين، الثقافة التظبيمية،

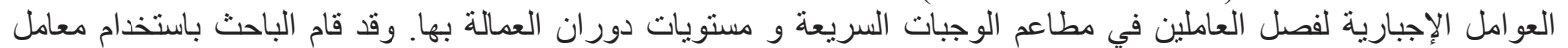

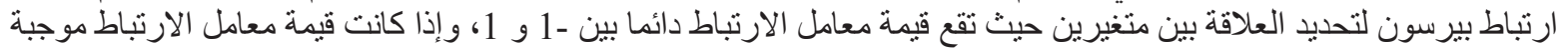

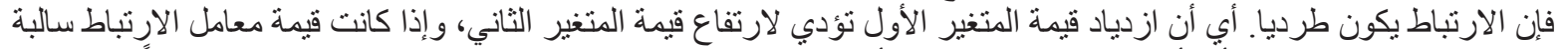

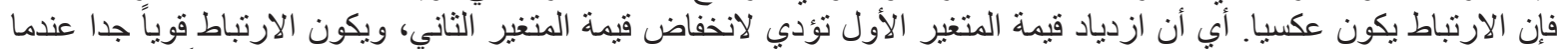

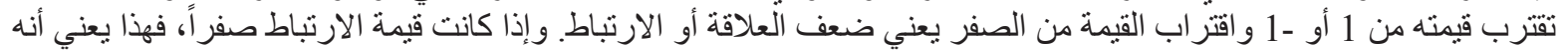
لا يوجد علاقة بين المتغيّرين.

محدّدات البحث

تم إجر اء الدر اسة الميدانيّة من شهر مارس 2012 إلى شهر يناير 2013، كما أن هنالك بعض المحدّدات الإجرائيّة لإدارات مطاعم عيّنة

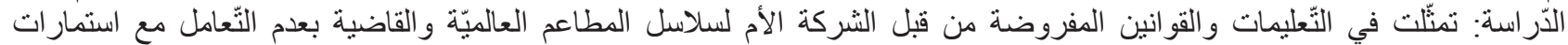

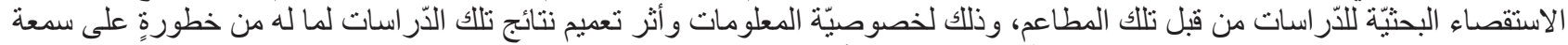

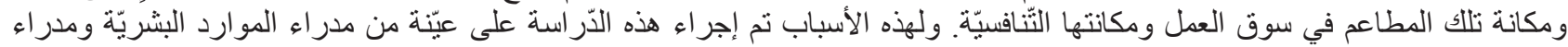
التشغيل لشركات مطاعم الوجبات السريعة البالغ عددهم (21). 
الإطار النظري و الدراسات السابقة

دوران العمالة

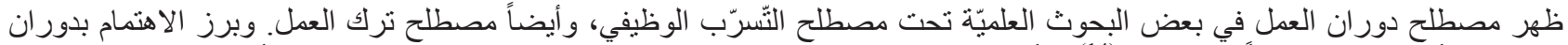

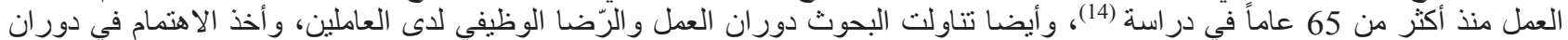

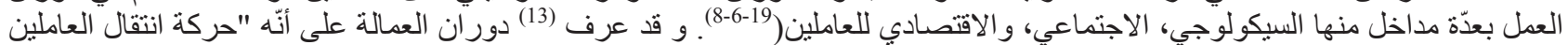

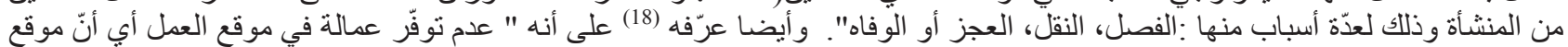

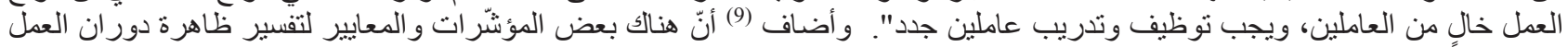
في المنشآتَ وهي :-

أ. عدم دقة عمليّات الاختيار و التّبيين بسبب الفصل و الاستغناء عن خدمات بعض العاملين. ب. هنآك حدّ مسموح به من دوران العمالة و الذي يجدد الحياة في المنشآت ويمدها بدماء جديدة قد تكون أكثر قدرة على الإبداع و النتّطوّر.

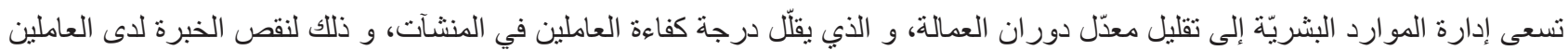

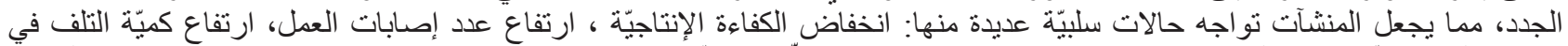

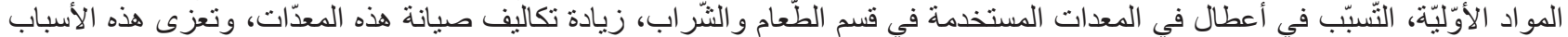

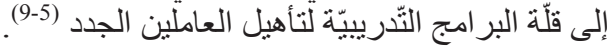

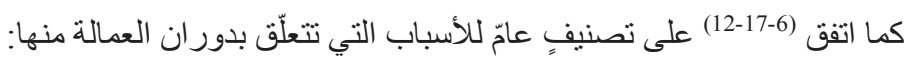
1 - 2- أسباب اقتصاديّة واجتماعيّة.

2- 20 - 2 أسباب فرديّة وتنظيميّة.

3- - أسباب داخليّة وخارجيّة.

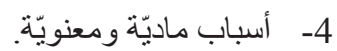

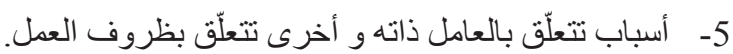

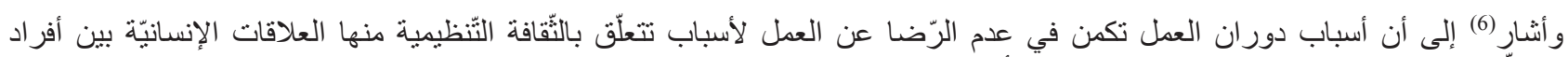

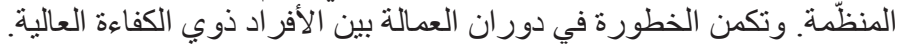

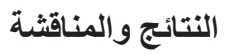

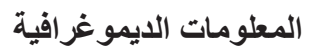

في ضوء المتغير ات يمكن وصف العو امل الثخصية والوظيفية لأفر اد عينة الدراسة على النحو التالي:

جدول رقم (1): يبين المعلومات الايموغر افية للعاملين في مطاعم الوجبات السريعة في عمان

\begin{tabular}{|c|c|c|c|}
\hline النسبة المئوية & التكر ار & \multicolumn{2}{|c|}{ العامل } \\
\hline 92 & 193 & ذكر & \multirow{2}{*}{ الجنس } \\
\hline 8 & 15 & أنثى & \\
\hline 100 & 208 & \multicolumn{2}{|c|}{ المجموع } \\
\hline النسبة المئوية & التكر ار & \multicolumn{2}{|c|}{ العامل } \\
\hline 87 & 181 & أعزب & \multirow{2}{*}{ الحالة الاجتماعية } \\
\hline 13 & 27 & متزوج & \\
\hline 100 & & \multicolumn{2}{|c|}{ المجموع } \\
\hline النسبة المئوية & التكر ار & \multicolumn{2}{|c|}{ العامل } \\
\hline 30 & 62 & 20 فأقل & \multirow{5}{*}{ الفئات العمرية } \\
\hline 37 & 76 & $25-21$ & \\
\hline 23 & 48 & $30-26$ & \\
\hline 10 & 22 & $35-31$ & \\
\hline- & - & 36 فأكثر & \\
\hline 100 & & \multicolumn{2}{|c|}{ المجموع } \\
\hline النسبة المئوية & التكر ار & \multicolumn{2}{|c|}{ العامل } \\
\hline 26 & 54 & ثانوية عامة & \multirow{4}{*}{ التحصيل العلمي } \\
\hline 39 & 81 & دبلوم & \\
\hline 35 & 73 & بكالوريوس & \\
\hline- & - & در اسات عليا & \\
\hline 100 & 208 & \multicolumn{2}{|c|}{ المجموع } \\
\hline
\end{tabular}


عبد الرحمن عبد الفتاح محمد بشار محمد النجداوي

\begin{tabular}{|c|c|c|c|}
\hline النسبة المئوية & التكر ار & \multicolumn{2}{|c|}{ العامل } \\
\hline 63 & 132 & 5 فما دون & \multirow{4}{*}{ الخبرة } \\
\hline 37 & 76 & $10-6$ & \\
\hline- & - & $15-11$ & \\
\hline- & - & 16 فأكثر & \\
\hline 100 & 208 & \multicolumn{2}{|c|}{ المجموع } \\
\hline النسبة المئوية & التكر ار & \multicolumn{2}{|c|}{ العامل } \\
\hline 40 & 83 & فنادق & \multirow{3}{*}{ لتخصص } \\
\hline 36 & 76 & سياحة & \\
\hline 24 & 49 & أخرى & \\
\hline 100 & 208 & \multicolumn{2}{|c|}{ المجموع } \\
\hline
\end{tabular}

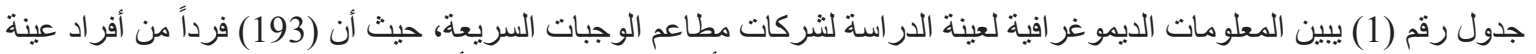

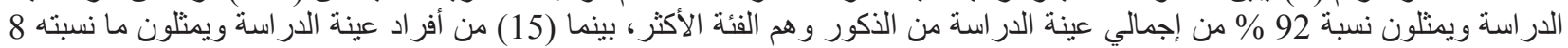

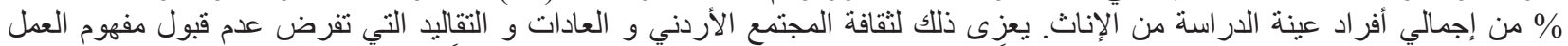

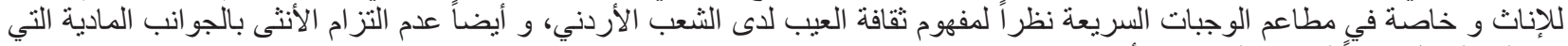

يتحملها العامل نظراً لطبيعة المجتمع الأردني.

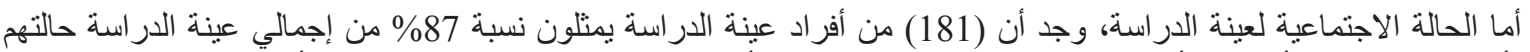

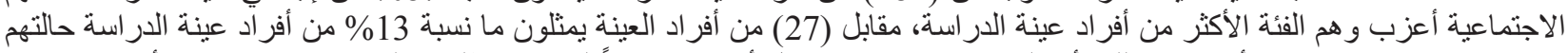

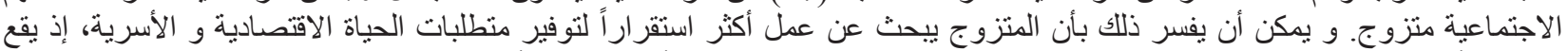

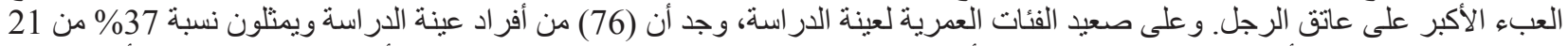

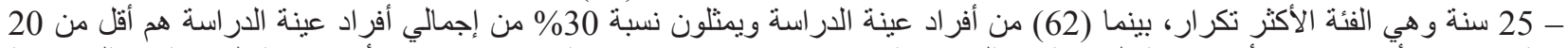

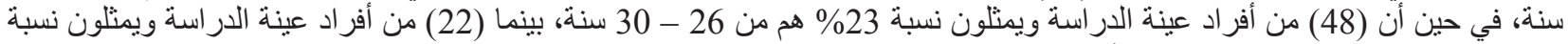

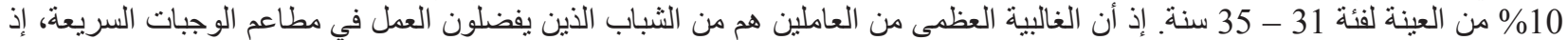
أنهم قادرين على آداء مهام الوظيفية تحت ضغط العمل، قد يمند لساعات عمل أكثر عن المعتاد.

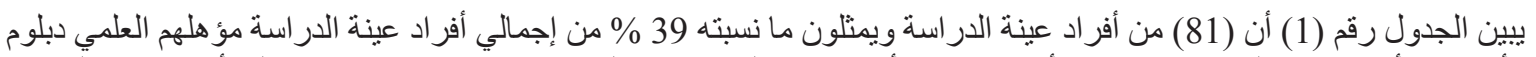

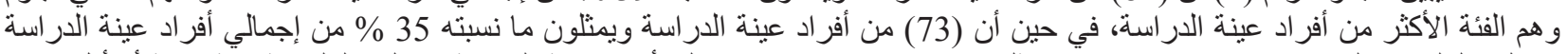

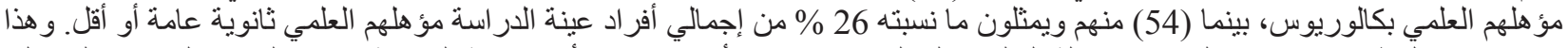

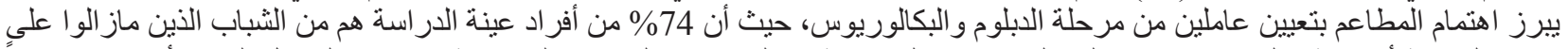

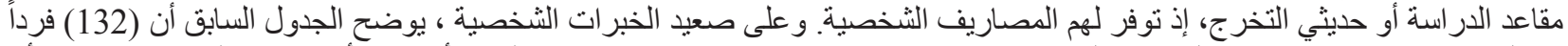

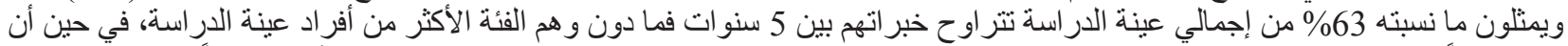

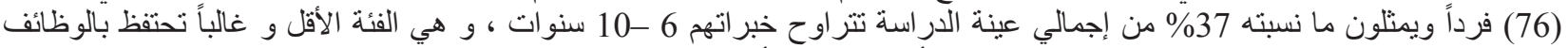

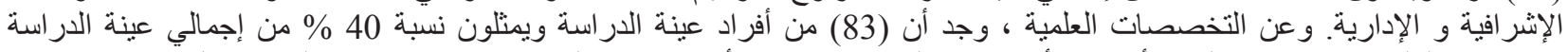

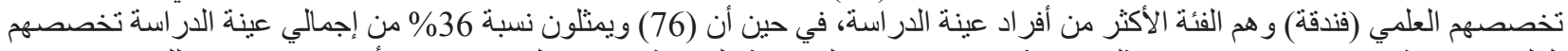

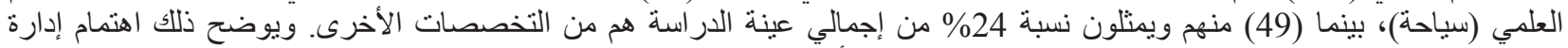

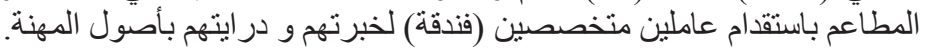

مناقشة رضا العاملين

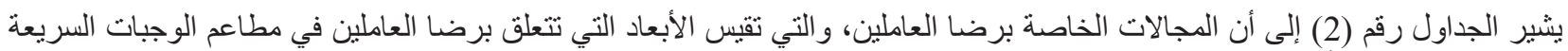
المتمثلة (الحوافز و الأجور ، التدريب، الر عاية الصحية، ضغط العملة).

جدول رقم (2): المتوسط الحسابي والانحر اف المعياري و النسبة المئوية الخاص بمجال الرضا العاملين لمطاعم الوجبات السريعة في عمان

\begin{tabular}{|c|c|c|c|c|}
\hline النسبة المئوية & الانحر افياري & الحستبط الحسي & 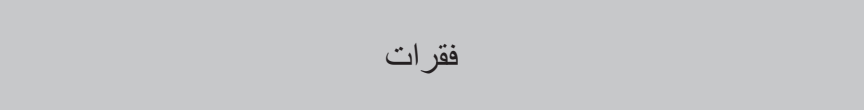 & رقم الفقرة \\
\hline \multicolumn{5}{|c|}{ الأجور و الحوافز } \\
\hline 91.9 & 0.71 & 4.60 & يستند نظام الحو افز و الأجور إلى أسس عادلة تعتمد على الكفاءة والخبرة & 1 \\
\hline 86.9 & 0.85 & 4.35 & يتم ربط حوافز العاملين بدرجة الجودة & 2 \\
\hline 91.9 & 0.67 & 4.60 & نظام الحوافز المتاحة يستند إلى مستوى الكفاءة والتدريب & 3 \\
\hline 90.7 & 0.78 & 4.54 & توفر الحوافز المعنوية بين العاملين & 4 \\
\hline 89.1 & 0.81 & 4.46 & كفاية الرواتب والأجور & 5 \\
\hline 73.9 & 1.82 & 3.70 & تخصيص وجبات غذائية للعاملين بصفة منتظمة & 6 \\
\hline 68.6 & 1.88 & 3.43 & لا يوجد صعوبة في ظروف العمل قد تدفعني لترك العمل في المطعم & 7 \\
\hline 77.6 & 1.61 & 3.88 & تهتم إدارة المطعم بتحقيق الاستقر ار النفسي لّى العاملين & 8 \\
\hline
\end{tabular}


دراسة بعض العوامل المؤثرة في دوران العمالة في مطاعم الوجبات السريعة في مدينة عمان

\begin{tabular}{|c|c|c|c|c|}
\hline 88.0 & 0.94 & 4.40 & تستند المنافسة في سوق العمل على الكفاءة & $\overline{9}$ \\
\hline 84.8 & 0.69 & 4.24 & \multicolumn{2}{|l|}{ الحوافز و الأجور ككل } \\
\hline \multicolumn{5}{|c|}{ 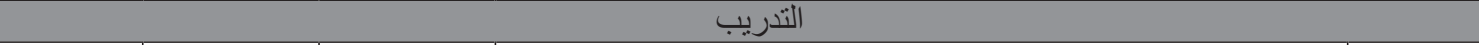 } \\
\hline 89.0 & 0.82 & 4.45 & يتم تصميم التندريب وفق لاحتياجات العاملين & 10 \\
\hline 87.0 & 0.92 & 4.35 & تسعى أساليب التنريب إلى التطوير المستمر لأداء العاملين و الإنتاج & 11 \\
\hline 90.0 & 0.80 & 4.50 & بالمنشسأة اهتمام الإدارة بالتدريب أيمانها بأهمية تطوير العنصر البشري & 12 \\
\hline 88.7 & 0.66 & 4.44 & \multicolumn{2}{|l|}{ التدريب ككل } \\
\hline \multicolumn{5}{|c|}{ 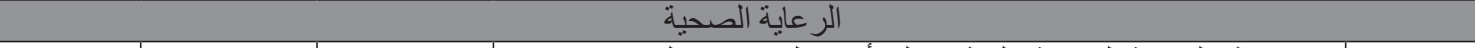 } \\
\hline 77.3 & 1.78 & 3.87 & تستند نظم الرعاية الصحية بالمطعم على أسس المتعارف عليها في & 13 \\
\hline 56.6 & 2.07 & 2.83 & تغطي الرعاية الصحية في المطعم كافة الأمر اض & 14 \\
\hline 83.9 & 1.53 & 4.20 & تغطي الرعاية الصحية كافة أفراد العائلة & 15 \\
\hline 77.2 & 1.72 & 3.86 & قيمة استقطاعات التامين الصحي مناسبة & 16 \\
\hline 73.8 & 1.26 & 3.69 & \multicolumn{2}{|l|}{ الرعاية الصحية ككل } \\
\hline \multicolumn{5}{|c|}{ ضغط العمل } \\
\hline 69.1 & 1.92 & 3.46 & لا يتم تجاوز ساعات العمل عن الساعات المحددة & 17 \\
\hline 86.9 & 1.21 & 4.35 & يوجد انتظام في جدول الورديات & 18 \\
\hline 80.8 & 1.61 & 4.04 & تركز الإدارة على (التندريب والخبرة ) لمواجهة ضغط العمل & 19 \\
\hline 78.9 & 2.77 & 3.95 & \multirow{2}{*}{\multicolumn{2}{|c|}{ جميع فقرات رضا العلمل كلين }} \\
\hline 82.3 & 2.45 & 4.12 & & \\
\hline
\end{tabular}

كما يظهر جدول رقم (2) نتائج عنصر الحو افز و الأجور والتي تراوحت متوسطاتها الحسابية بين 3.43 للفقرة رقم (7) و والتي

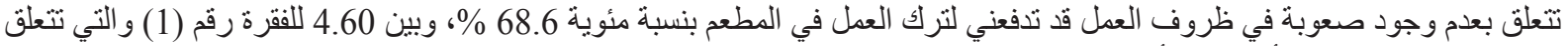

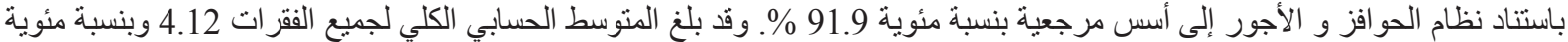

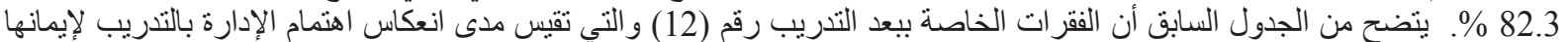

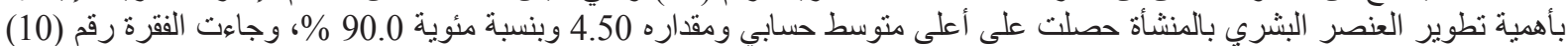

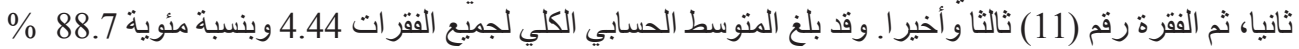

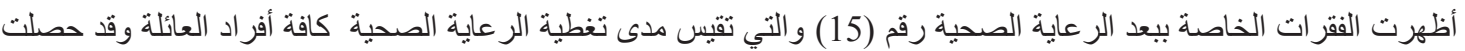

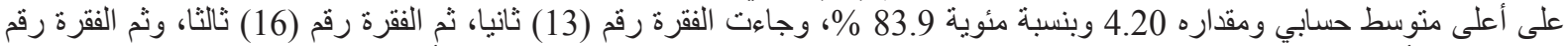

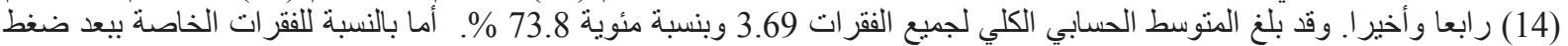

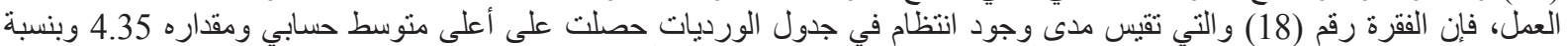

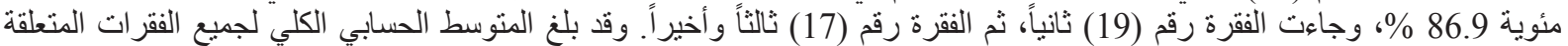

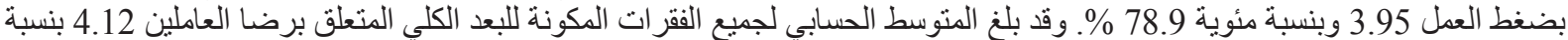
مئوية 82.3 \%. وتتفق الدر اسة مع دراسة (3) وجود علاقة قوية إيجابية بين ضغوط العمل للعاملين وبين مستوى دور التئ العمالة.

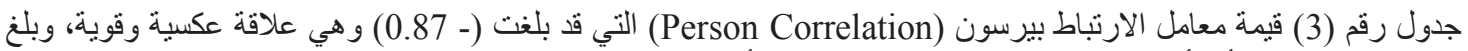

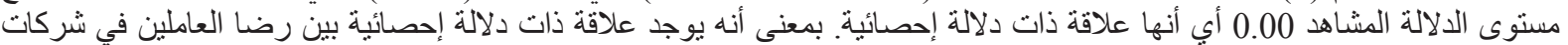

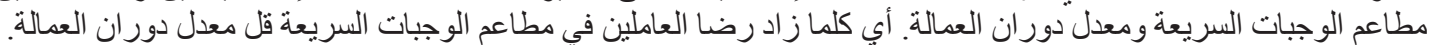

جدول رقم (3): نتائج اختبار بيرسون للارتباط (Person Correlation) بين دوران العمالة وبين رضا العاملين في مطاعم الوجبات السريعة

\begin{tabular}{|c|c|c|}
\hline مستوى الدلالة المشاهد & قيمة الارتباط بين الأبعاد وبين دوران العمالة & 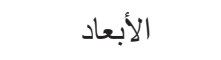 \\
\hline 0.00 & $0.73-$ & الحوافز و الأجور \\
\hline 0.00 & $0.82-$ & 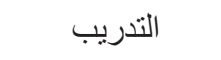 \\
\hline 0.00 & $0.68-$ & الر الرعاية الصحية \\
\hline 0.00 & 0.79 & ضغط العمل \\
\hline 0.00 & $0.87-$ & رضا العاملين ككل \\
\hline
\end{tabular}


يشير الجدول رقم (4) إلى المجالات الخاصة بالثقافة التنظيمية، التي تقيس الأبعاد التي تتعلق بالثقافة التتظيمية المتمثلة (علاقات زملاء العمل، تفويض السلطة، العدالة التنظيمية، و الأنظمة و التعليمات) لمطاعم التوجبات السريعة في عمان.

جدول رقم (4): المتوسط الحسابي والانحراف المعياري و النسبة المئوية بمجال الثقافة التنظيمية لمطاعم الوجبات السريعة في عمان

\begin{tabular}{|c|c|c|c|c|}
\hline المئوية النسبة \% & الالمعراف & الحسابي & الفقرات & رقم الفقرة \\
\hline \multicolumn{5}{|c|}{ علاقات زملاء العمل } \\
\hline 83.2 & 0.96 & 4.16 & أن زملائي في العمل بتعاملون معي بسلوكيات مقبولة & 20 \\
\hline 80.1 & 1.16 & 4.01 & بيناقتشني رؤسائي حول القرار ات المتعلقة بعملي & 21 \\
\hline 70.3 & 1.41 & 3.52 & اشعر بنز اهة المشرف في حسم النزاعات بين المرؤوسين & 22 \\
\hline 76.3 & 1.34 & 3.82 & ير ير اعي رؤسائي مصلحتي في القرارات المرتبطة بالعمل & 23 \\
\hline 77.5 & 0.89 & 3.88 & \multicolumn{2}{|l|}{ علاقات زملاء العمل ككل } \\
\hline \multicolumn{5}{|c|}{ 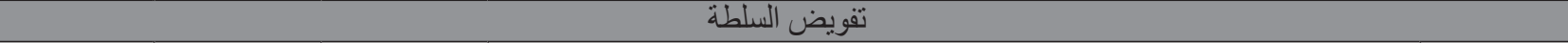 } \\
\hline 75.2 & 1.37 & 3.76 & يتم استخذام سباسة تفويض السلطة في العمل & 24 \\
\hline 83.2 & 0.92 & 4.16 & يسهر تفويض السلطة في الثعور بالمسؤولية & 25 \\
\hline 83.6 & 0.98 & 4.18 & بيسهم تفويض السلطة في رفع كفاءة العاملين في العمل وحل المشاكل الطارئة & 26 \\
\hline 83.3 & 0.98 & 4.17 & بسهر تفويض السلطة بتوفير الكوادر القادرة على الإدارة و القبادة & 27 \\
\hline 81.3 & 0.75 & 4.07 & \multicolumn{2}{|l|}{ تفويض السلطة ككل } \\
\hline \multicolumn{5}{|c|}{ 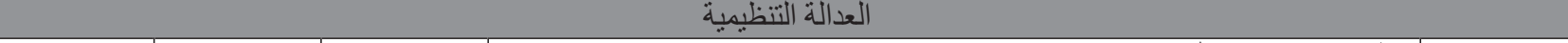 } \\
\hline 83.1 & 0.95 & 4.16 & نظام الإجاز ات عادل & 28 \\
\hline 82.6 & 0.94 & 4.13 & توفر العدالة بين العاملين & 29 \\
\hline 83.5 & 0.82 & 4.18 & العدالة تؤدي إلى زيادة ولائي وانتمائي للعمل & 30 \\
\hline 80.2 & 0.78 & 4.01 & أشُعر بأن الإجر اءات الإدارية المطبقة تتسم بالعدالة & 31 \\
\hline 82.0 & 1.03 & 4.10 & يوجد إجر اءات عادلة لملاحقة التجاوز ات & 32 \\
\hline 83.4 & 0.82 & 4.17 & اششعر بأن سلوك رؤسائي يتس بالإنصاف و العدالة & 33 \\
\hline 82.6 & 0.68 & 4.13 & \multicolumn{2}{|l|}{ العدالة التنظيمية ككل } \\
\hline \multicolumn{5}{|c|}{ الانظمة و التعليمات } \\
\hline 84.1 & 0.78 & 4.21 & يتم تطبيق قو انين التوظيف الخاصة طبقاً للتشريعات و قانون العمل & 34 \\
\hline 81.0 & 1.14 & 4.05 & يستند نظام إنهاء الخدمات على قو انين وتعليمات العمل & 35 \\
\hline 82.6 & 0.73 & 4.13 & \multicolumn{2}{|l|}{ الأنظمة و التعليمات ككل } \\
\hline 81.3 & 0.54 & 4.07 & \multicolumn{2}{|l|}{ جميع فقرَات الثقافْة التنظيمية } \\
\hline
\end{tabular}

يشير جدول رقم (4) إلى الفقر ات الخاصة ببعد العلاقات بين العاملين في مطاعم الوجبات السريعة، ويتضح منه أن الفقرة رقم (20)

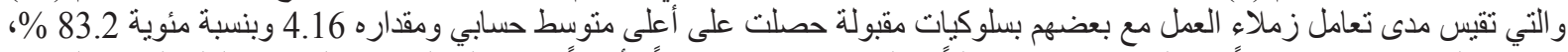

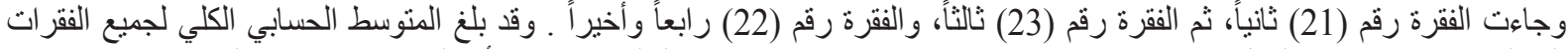

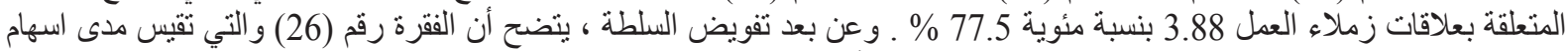

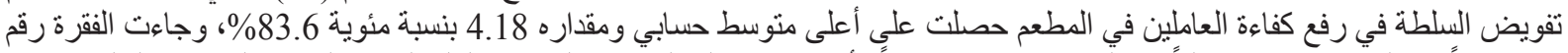

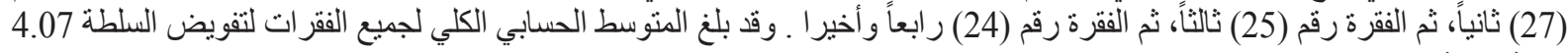

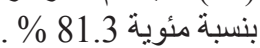

وتتبير الفقرة الخاصة ببعد العدالة التنظيمية رقم (30) والتي تتعلق بددى تعلق توفر العدالة بزيادة الو لاءو والانتماء للمطعم حصلت

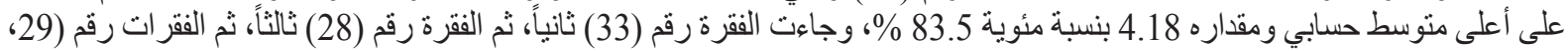

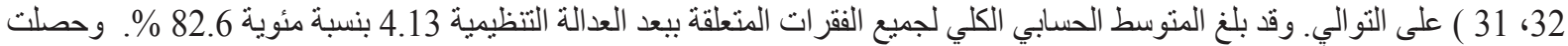

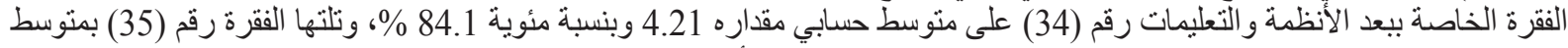

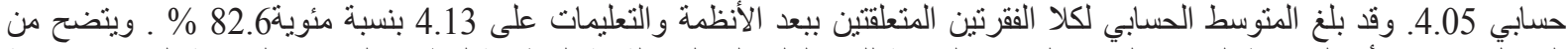

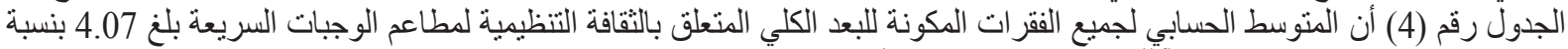

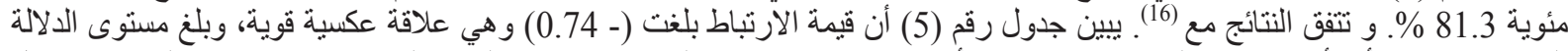

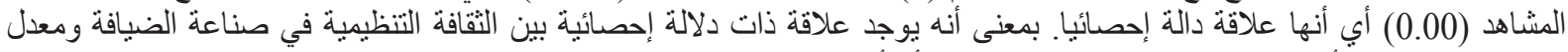

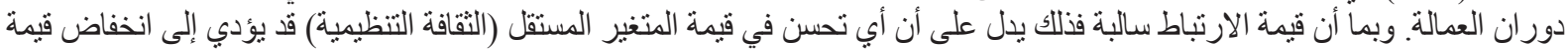

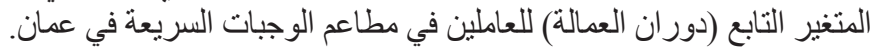


جدول رقم (5): نتائج اختبار بيرسون للارتباط بين دوران العمالة والثقافة التظيمية في مطاعم الوجبات السريعة في عمان

\begin{tabular}{|c|c|c|}
\hline مستوى الدلالة المشاهد & قيمة الارتباط بين الأبعاد وبين دور ان العمالة & 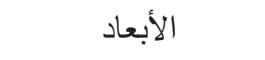 \\
\hline 0.00 & -0.79 & علاقات زملاء العمل \\
\hline 0.00 & -0.75 & تفويض السلطة \\
\hline 0.00 & -0.87 & 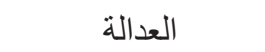 \\
\hline 0.00 & -0.83 & الأنظمة و التعليمات \\
\hline 0.00 & -0.74 & الثقافة التنظيمية ككل \\
\hline
\end{tabular}

العوامل الإجبارية لفصل العاملين

يعرض الجدول رقم (6) الفقرات المتعلقة بالعو امل الإجبارية لفصل العاملين، حيث تظهر الفقرة رقم (40) و والتي تقبس مخالفة قو اعد الأمانة

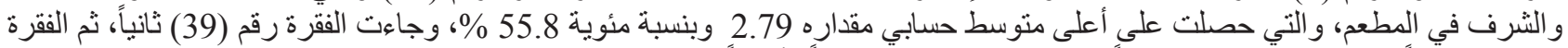

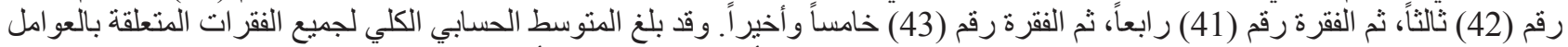

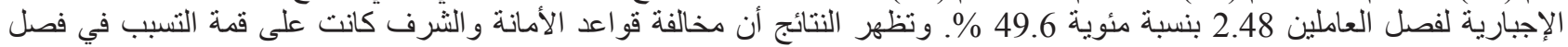

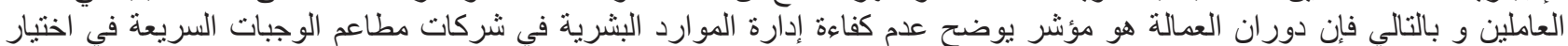
عاملين يتصفو ا بالأمانة و الثرف في في العمل و السلوك السلبي لدى العاملين. ويتفق ذلك مع (15).

يثير جدول رقم (7) إلى أن هنالك علاقة ارتباط موجبة ذات دلالة إحصائية عند مستوى الدلالة (0.05)، حيث تبين الإنين أن قيمة معامل

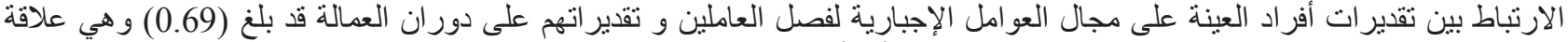

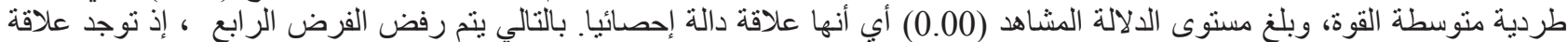
طردية ذات دلالة إحصائية بين توفر العوامل الإجبارية لفصل العاملين في شركات مطاعم الوجبات السيات السريعة و معدل دوران العمالة.

جدول رقم (7): نتائج اختبار بيرسون للارتباط بين دوران العمالة وبين العوامل الإجبارية لفصل العاملين في مطاعم الوجبات السريعة في عمان

\begin{tabular}{|c|c|c|}
\hline مستوى الدلالة المشاهد & قيمة الارتباط بين الأبعاد وبين دور ان العمالة & 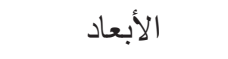 \\
\hline 0.00 & 0.69 & العو امل الإجبارية \\
\hline
\end{tabular}

قياس معدل دوران العمالة في شركات مطاعم الوجبات السريعة في مدينة عمان

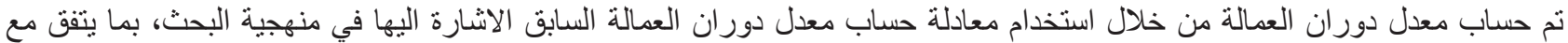

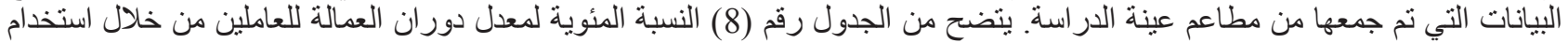

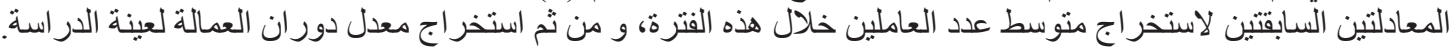


عبد الرحمن عبد الفتاح محمد بشار محمد النجداوي

جدول رقم (8): معدل دوران العمالة للعاملين في مطاعم الوجبات السريعة

\begin{tabular}{|c|c|c|c|c|c|c|c|c|c|}
\hline 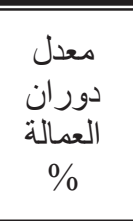 & متوسط العاملين & م العتوسط & الجاملين & التاركين & مجموع العاملين & السنةد العاملين نهاية & $\begin{array}{c}\text { عدد العاملين } \\
\text { السنة/12/1/12012 }\end{array}$ & \multicolumn{2}{|c|}{ أسم المطعم } \\
\hline 16.822 & 53.5 & 9 & 12 & 3 & 107 & 52 & 55 & ماكدو نالدز & 1 \\
\hline 56.667 & 30 & 17 & 14 & 10 & 60 & 25 & 35 & تشيلي ويز & 2 \\
\hline 16.667 & 45 & 7.5 & 15 & 0 & 90 & 45 & 45 & فر ابد تشطن & 3 \\
\hline 34.545 & 55 & 19 & 18 & 10 & 110 & 50 & 60 & بوبايز & 4 \\
\hline 31.646 & 39.5 & 12.5 & 15 & 5 & 79 & 37 & 42 & برجر كنج & 5 \\
\hline 17.778 & 45 & 8 & 16 & 0 & 90 & 45 & 45 & هارديز & 6 \\
\hline 25.862 & 58 & 15 & 22 & 4 & 116 & 56 & 60 & دجاج كنتاكي & 7 \\
\hline 26.027 & 36.5 & 9.5 & 13 & 3 & 73 & 35 & 38 & دومينز بيتز ا & 8 \\
\hline 39.474 & 19 & 7.5 & 11 & 2 & 38 & 18 & 20 & صب ويز & 9 \\
\hline 22.727 & 22 & 5 & 10 & 0 & 44 & 22 & 22 & نشلي هاوس & 10 \\
\hline 20 & 45 & 9 & 18 & 0 & 90 & 45 & 45 & الصنير & 11 \\
\hline 24.051 & 39.5 & 9.5 & 17 & 1 & 79 & 39 & 40 & بيتزا هت & 12 \\
\hline 30.526 & 47.5 & 14.5 & 19 & 5 & 95 & 45 & 50 & الطازج & 13 \\
\hline 43.396 & 26.5 & 11.5 & 9 & 7 & 53 & 23 & 30 & بابا جونز & 14 \\
\hline 29.268 & 20.5 & 6 & 6 & 3 & 41 & 19 & 22 & شبس اند & 15 \\
\hline 25 & 22 & 5.5 & 7 & 2 & 44 & 21 & 23 & شيكس اند & 16 \\
\hline 24.324 & 18.5 & 4.5 & 7 & 1 & 37 & 18 & 19 & فورماجي & 17 \\
\hline 13.636 & 22 & 3 & 6 & 0 & 44 & 22 & 22 & لا بوفيه & 18 \\
\hline 13.889 & 18 & 2.5 & 5 & 0 & 36 & 18 & 18 & كويك ميل & 19 \\
\hline 12 & 25 & 3 & 6 & 0 & 50 & 25 & 25 & ستيك اند & 20 \\
\hline 15 & 20 & 3 & 6 & 0 & 40 & 20 & 20 & كامبولر & 21 \\
\hline 25.681 & & & & & العمالا & متو سط معدا & & & \\
\hline
\end{tabular}

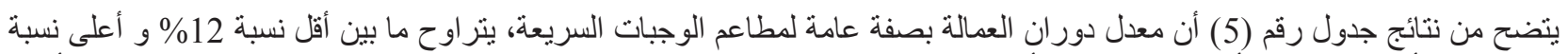

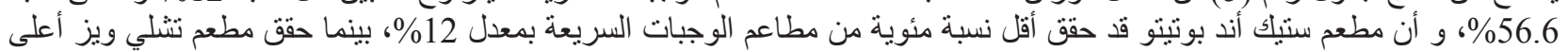

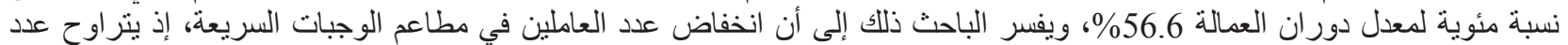

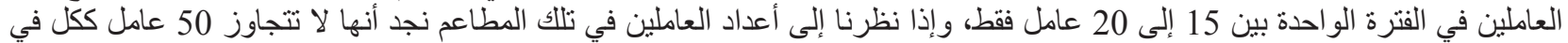

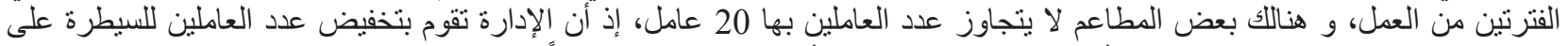

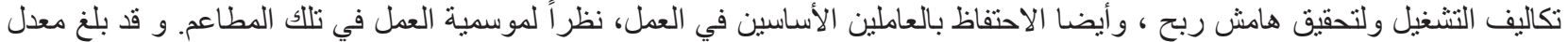
دوران العمالة ككل 25.6\% لمطاعم الوجبات السريعة في عمان. 


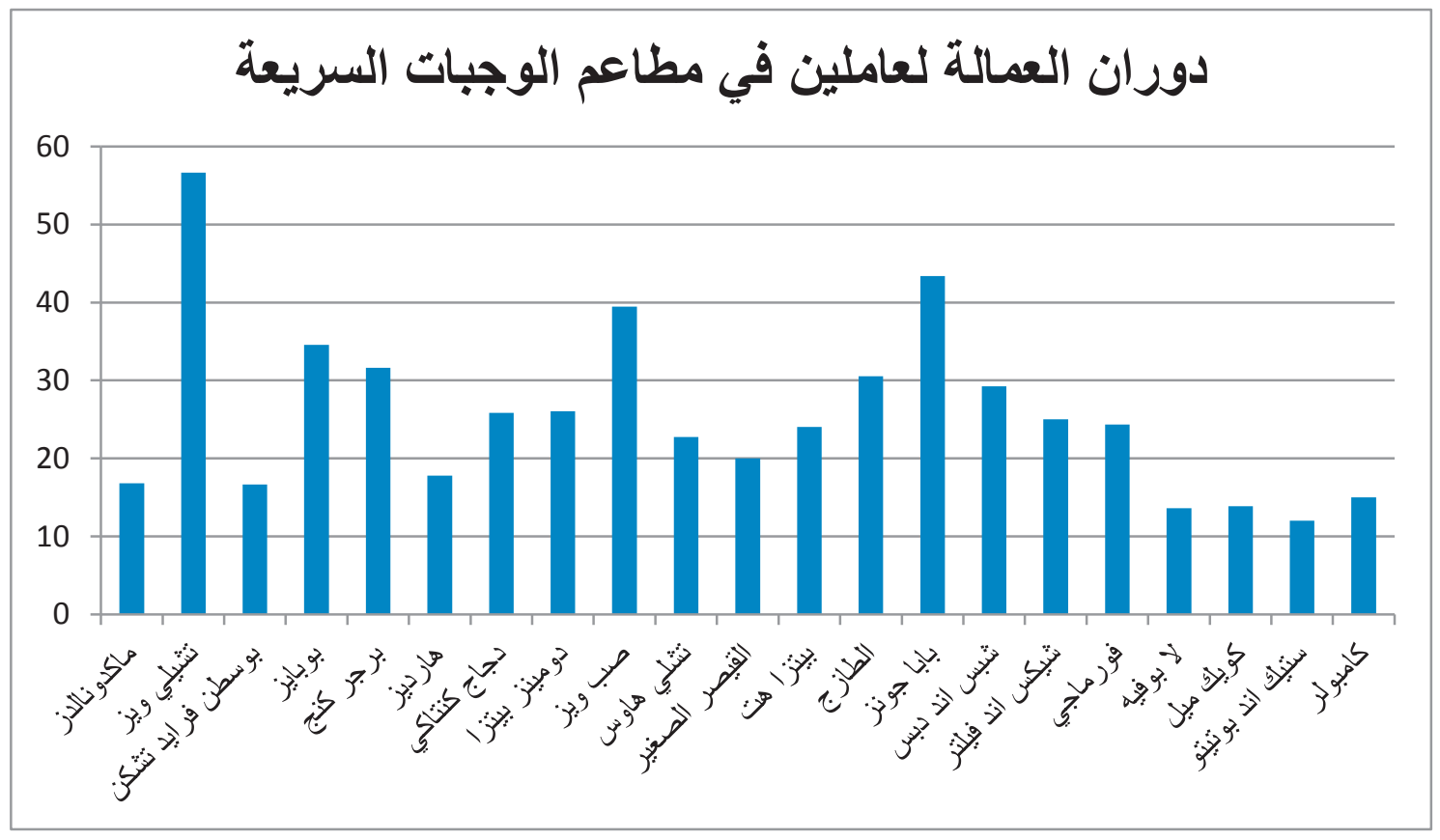

شكل رقم (1): يوضح النسبة المئوية لمعدلات دوران العمالة للعاملين في مطاعم الوجبات السريعة:

خلاصة النتائج

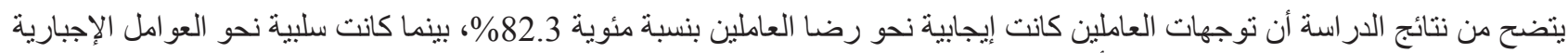

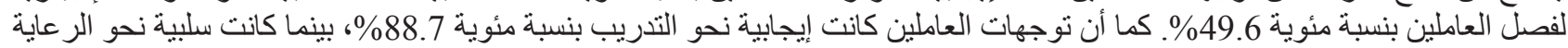

الصحية في فنادق عينة الدر اسنة.

التوصيات

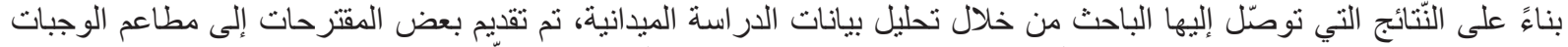

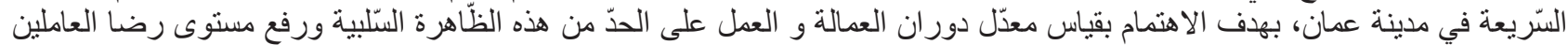

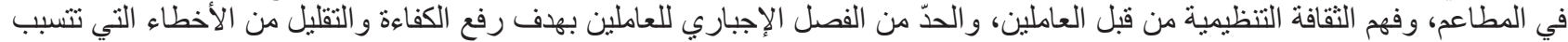
بفضلهم من العمل، على النّّو التالي:

1- التقليل من ضغط العمل عن طريق الحو افز الماديّة والمعنوية للعاملين لتغطية ساعات العمل الإضافية.

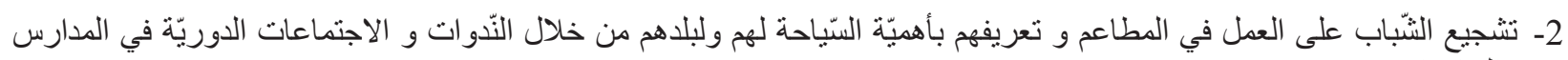
و والجامعات. 3- رفع كفاءة العاملين من خلال التدريب الجيد للعاملين؛ وصقل مهارات العاملين للتقليل من الأخطاءو معدّلات الحوادث و الإصابات في العمل.

4- وضع بر امج تو عويّة للعاملين للحفاظ على قو اعد الأمانة و عدم الإخلال بها وما يتسبب من مشاكل للعامل و المطعم معاً.

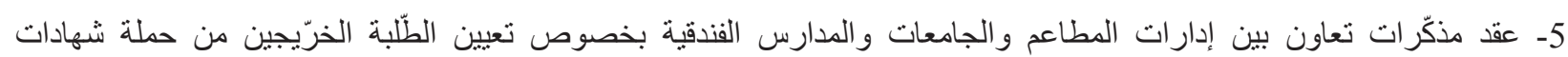

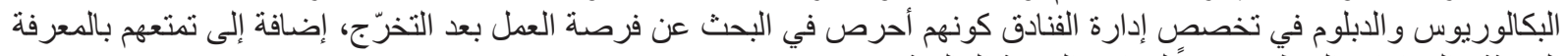
الحديثة والمهارات المتطوّرة وفقاً لمعايير الخدمة العالمئة.

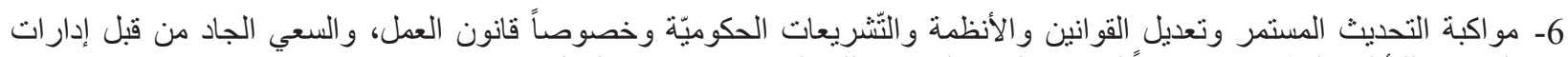
المطاعم للتأقلم و التكيّف معها سعياً لتحسين الحياة الوظيفية للعاملين وتحسين بيئة العمل.

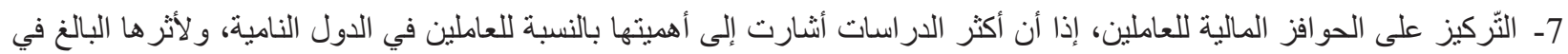

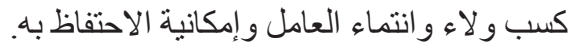

8- تفعيل دور السلف النقدية للعاملين بشكل شهري لضمان تخفيف المعاناة المعيشية؛ وتمكين العامل من تسديد بعض التزاماتاته المالية للغير، و هذا النوع وبشكل غير مباشر يلزم العامل البقاء لفترة أطول لحين تسديد مبالغ السلفة. 9- إثراء العمل بعتبر من الأمور الأكثر أهمبة لتحسين بيئة العمل للعاملين وبالتالي تحسين نظرتهم نحو العمل وسعيهم الجاد لإنجاز و واجباتهم ومهامهم بر غبة وفاعلية. 


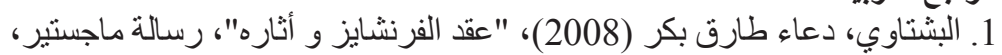

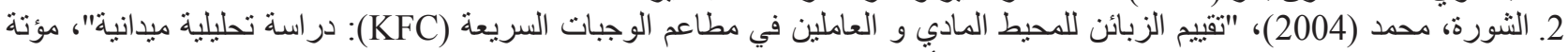
للابحوث و الدراسات، المجلد التاسع، العدد الثاني، الأردن.

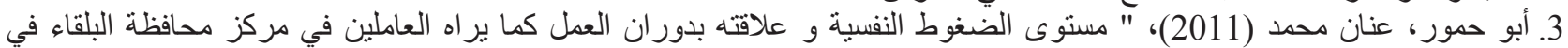

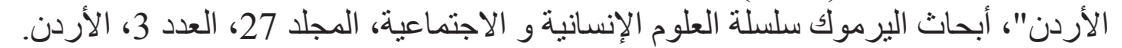

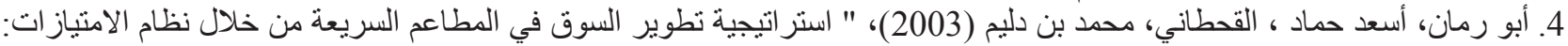

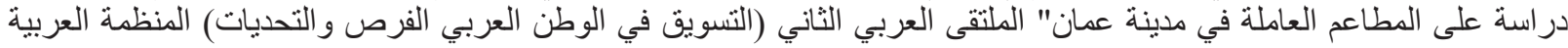

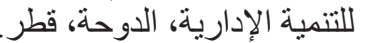

5. الجميلي، قصي (2010)، " إدارة الموارد البشرية في المنثآت السياحية و الفندقية" دار الصفاء للنشر و التوزيع، عمان، الأردن.

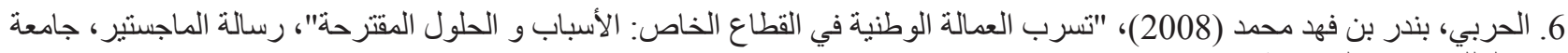
الملك سعود، السعودية.

7. القريني، حسين بن عبد الله بن ناصر (2010)، "أنماط توزيع مطاعم الوجبات السريعة في مدينة الرياض"، رسالة دكتور اه، جامعة الإمام

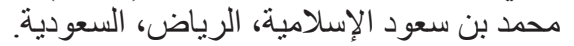

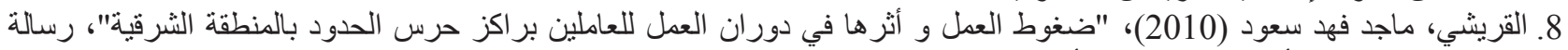
ماجستير، جامعة الأمير نايف للعلوم الأمنية.

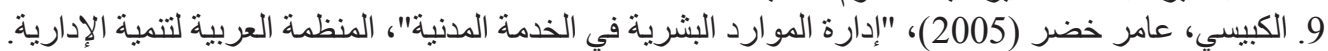

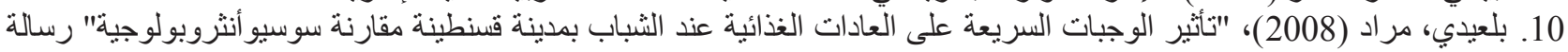
ماجستير ، جامعة قسنطينة، الجز ائر.

11. جمعية المطاعم الوطنية، الو لايات المتحدة الأمريكية 20011

12. حويلة، محمد فتوح محمد (2001)، "دراسة معدل دوران العانة العاملين فى مطاعم الوجبات السريعة"، رسالة ماجستير ، جامعة حلوان، جمهورية مصر العربية.

13. شاويش، مصطفى نجيب (2000)، "إدارة الموارد البشرية (إدارة الأفراد)" الطبعة الثالثة ، دار الثروق للنشر التوزيع عمان ،

14. Brayfield, Arthur H.; Crockett, Walter H.(1955), "Employee attitudes and employee performance", Psychological Bulletin, Vol 52(5), Sep 1955, 396-424

15. Dessler, Gary (2010), "Human Resource Management", $12^{\text {th }}$ Edition, by Prentice Hall

16. Koutroumanis \& George Alexakis (2009), "Organizational Culture in the Restaurant Industry: Implications for Change", Journal of Organizational Culture, Communications and Conflict, Volume 13, No. 2,

17. Mobley, W. H. (1982). Some unanswered questions in turn-over and withdrawal research. Academy of Management Review, vol 7, no 1 111-116

18. Woods, Robert, H. (1995), "Managing Hospitality Human Resources", Michigan Educational Institute of the American Hotel and Motel Association.

19. Zheng WeiBo, Sharan Kaur \& Tao Zhi (2010), " A critical review of employee turnover model (1938-2009) and development in perspective of performance", African Journal of Business Management Vol. 4(19), pp. 4146-4158,

\section{A Study of Some Factors Affecting Employee Turnover in Fast Food Restaurant in Amman}

This article aims to study some factors effects on employee turnover in fast food restaurants in Amman city, namely employees satisfaction (incentives and wages, training, health care, job stress), organizational culture (coworkers relationships, empowerment, organizational justice, regulations and instructions), and involuntary termination factors. The results showed that employees satisfaction has got the highest correlation effect in employee turnover compared with other factors. And the study revealed that the employee turnover rate in the fast food restaurants was, $25.68 \%$. Based on the findings of the research have been proposed a set of recommendations addressed to the managers of fast food restaurants, in order to reduce labor turnover.

Keywords: Employee Turnover, Fast food Restaurant, Amman 